\title{
Caracterização morfológica dos frutos, das sementes e do desenvolvimento das plântulas de Jatropha elliptica Müll. Arg. (Euphorbiaceae) ${ }^{1}$
}

\author{
LUCIANA M.M. AÑEZ2, MARIA F.B. COELHO ${ }^{2,3}$, MARIA C.F. ALBUQUERQUE² e \\ JEFERSON L.D. DOMBROSKI ${ }^{2}$
}

(recebido: 4 de julho de 2003; aceito: 21 de junho de 2005)

\begin{abstract}
Fruit, seed and seedling morphology of Jatropha elliptica Müll. Arg. (Euphorbiaceae)). The aim of this work was to describe the morphology of the fruit, the seed and the development of the seedling of Jatropha elliptica Müll. Arg. The fruits were collected in September and October (2002), in the Experimental Farm at Universidade Federal Mato Grosso, in Santo Antonio de Leverger-MT. 50 fruits and 50 seeds were utilized to describe the fruit and the seed morphology. For the characterization of the germination stages, four repetitions of 20 seeds were used, sowning upon blot paper, in clear plastic boxes, moisten with giberelic acid (400 ppm), kept in a germination chamber, at $30^{\circ} \mathrm{C}$ and with an eight hours photoperiod, during 45 days. The fruit of J. elliptica is dry, with three cocas, a hard endocarp, and shows an explosive dehiscence. The seed is oval, albuminous, has a smooth testa and a marmoreal color, with a caruncule in the ventral part, a visible hilum in the base and the distinct longitudinal rafe. The germination is epigeous and phanerocotyledonal. The germination average time is from 13 to 25 days. It was possible to describe and to illustrate, in a distinct form, J. elliptica fruit, seed and seedling morphologies, which behaved in a sufficiently homogeneous and trustworthy way for the identification.
\end{abstract}

Key words - germination, Jatropha elliptica, medicinal plants, morphology

RESUMO - (Caracterização morfológica dos frutos, das sementes e do desenvolvimento das plântulas de Jatropha elliptica Müll. Arg. (Euphorbiaceae)). O objetivo deste trabalho foi descrever a morfologia do fruto, da semente e do desenvolvimento de plântulas de Jatropha elliptica Müll. Arg. Os frutos foram coletados em setembro e outubro de 2003, na Fazenda Experimental da Universidade Federal de Mato Grosso, no Município de Santo Antônio de Leverger. Para a descrição da morfologia dos frutos e das sementes foram utilizados 50 frutos e 50 sementes. Para a caracterização das etapas da germinação foram utilizadas quatro repetições de 20 sementes, colocadas sobre papel mata-borrão, umedecidas com ácido giberélico (400 ppm), em caixas de plástico transparente, mantidas em câmara para germinação, a $30^{\circ} \mathrm{C}$ e fotoperíodo de oito horas, durante 40 dias. $\mathrm{O}$ fruto de J. elliptica é seco, tricoca, endocarpo lenhoso e de deiscência explosiva. A semente é ovalada, endospérmica, de envoltório liso e marmoreado, com carúncula presa na parte ventral; o hilo é visível na base e a rafe é bem marcada longitudinalmente. A germinação é epígea e fanerocotiledonar. O tempo médio de germinação é de 13 a 25 dias. Foi possível descrever e ilustrar, de forma distinta, a morfologia do fruto, da semente e da plântula de J. elliptica, que se apresentou bastante homogênea e confiável para a identificação.

Palavras-chave - germinação, Jatropha elliptica, morfologia, planta medicinal

\section{Introdução}

Os estudos sobre morfologia de plântulas têm merecido atenção há algum tempo, quer seja como parte de estudos morfo-anatômicos, objetivando ampliar o conhecimento sobre determinada espécie ou grupamento sistemático vegetal, quer visando o reconhecimento e identificação de plântulas de uma certa região dentro de um enfoque ecológico (Oliveira 1993).

\footnotetext{
1. Parte da dissertação de mestrado do primeiro autor.

2. Universidade Federal de Mato Grosso, Faculdade de Agronomia e Medicina Veterinária, Departamento de Fitotecnia e Fitossanidade, Av. Fernando Correa da Costa s.n., 78060-900 Cuiabá, MT, Brasil.

3. Autor para correspondência: coelhomf@terra.com.br
}

A importância do conhecimento sobre o comportamento germinativo e o desenvolvimento das plântulas foi demonstrada por Labouriau et al. (1963), quando utilizaram as características morfológicas de plântulas para estudar a regeneração natural do cerrado, identificando as espécies que regeneravam a partir de sementes pela observação das plântulas que apresentavam evidências de germinação.

Alguns autores citaram as dificuldades de identificar plantas no estádio juvenil, porque as características morfológicas externas no início do desenvolvimento são diferentes da planta adulta, além do que, plântulas de espécies afins normalmente apresentam semelhanças nas características externas, dificultando ou até impossibilitando a identificação (Silva et al. 1995).

Damião Filho (1993) ressaltou que a interpretação das estruturas da planta jovem é de fundamental 
importância quando se faz necessária a mensuração dos diferentes estádios de crescimento da planta. A partir de estudos morfológicos de sementes e plântulas, pode-se, ainda, obter informações sobre germinação, armazenamento, viabilidade e métodos de semeadura (Ferreira et al. 1998).

Jatropha elliptica Müll. Arg., conhecida popularmente como purga-de-lagarto, foi estudada fitoquimicamente, devido sua importância medicinal. Sua raiz é depurativa e usada na medicina popular contra doenças venéreas, coceiras e picada de cobra (van den Berg \& Silva 1988, Pott \& Pott 1994).

A maioria dos estudos sobre J. elliptica está relacionada a aspectos etnobotânicos e farmacológicos, o que deixa lacunas, principalmente no que se refere à ecologia, cultivo e conservação da espécie. Por ser uma espécie de importância social, que apresenta amplo uso popular, com alta pressão antrópica, e ser obtida exclusivamente por extrativismo, pesquisas sobre a mesma são consideradas prioritárias (Vieira et al. 2002).

Guarim Neto (1996), De La Cruz-Mota (1997), Souza (1998) e Añez (1999), por meio de pesquisas etnobotânicas em Mato Grosso, confirmaram o uso de J. elliptica na medicina tradicional desta região. Estudos farmacológicos identificaram um diterpeno, a jatrofona, como principal constituinte ativo da espécie. Dutra et al. (1996) comprovaram que esse princípio ativo inibe marcadamente a agregação de plaquetas em humanos e também em diferentes espécies animais. Santos \& Sant'Ana (1999) estudaram o efeito da jatrofona extraída do rizoma desta planta no controle do caramujo Biomphalaria glabrata, enquanto que Martini et al. (2000) descreveram os efeitos neuroquímicos deste diterpeno. Silva et al. (1998) analisaram os aspectos fenológicos de J. elliptica ao longo de um ano em uma população nativa. Concluíram que a espécie apresenta padrão fenológico sazonal do tipo semidecíduo, com produção de frutos e sementes sadias, principalmente durante a transição da estação seca para chuvosa.

O objetivo deste trabalho foi estudar a morfologia do fruto, da semente e do desenvolvimento de plântulas de Jatropha elliptica Müll. Arg., provendo subsídios à germinação e identificação dos primeiros estágios de desenvolvimento desta espécie.

\section{Material e métodos}

Jatropha elliptica Müll. Arg. conhecida popularmente como purga-de-lagarto ou erva-de-teiú é uma espécie herbáceo-subarbustiva (Silva et al. 1998), da família
Euphorbiaceae, que ocorre no cerrado dos Estados de Mato Grosso, de Goiás e da Bahia. Apresenta um a cinco ramos por planta, cada ramo com altura variando de $1,5 \mathrm{~cm}$ (brotação nova) a $81 \mathrm{~cm}$, e o diâmetro dos ramos ao nível do solo de $2,3 \mathrm{~mm}$ a $8,1 \mathrm{~mm}$. O padrão fenológico é sazonal do tipo semidecíduo, com produção de frutos e sementes sadias, principalmente durante a transição da estação seca para chuvosa (Silva et al. 1998).

Os frutos foram coletados manualmente, de forma aleatória, numa área de aproximadamente dois hectares, em uma população natural na Fazenda Experimental da Universidade Federal de Mato Grosso (UFMT), localizada no município de Santo Antônio de Leverger - MT, com coordenadas de $15^{\circ} 47^{\prime} \mathrm{S}$ e $56^{\circ} 04^{\prime} \mathrm{W}$ e altitude de 140 metros acima do nível do mar, em setembro e outubro de 2003. A exsicata do material vegetal utilizado neste trabalho está depositada no Herbário Central da Universidade Federal de Mato Grosso sob n ${ }^{\circ} 25656$.

Para a coleta de sementes, sacos de tule foram amarrados aos frutos a fim de evitar a dispersão. Após a coleta, as sementes foram acondicionadas em sacos de papel e armazenadas no Laboratório de Análise de Sementes da Faculdade de Agronomia e Medicina Veterinária (FAMEV/UFMT), em câmara com temperatura de $17,5^{\circ} \mathrm{C}$ e umidade relativa de $76,87 \%$.

Para a descrição da morfologia dos frutos e das sementes foram utilizados 50 frutos e 50 sementes, coletados em 30 indivíduos. Os frutos foram descritos considerando-se os seguintes aspectos: dimensões, tipo, cor, textura, deiscência e número de sementes por fruto. No estudo da semente, as características externas observadas foram: dimensões, cor e textura do envoltório e presença de carúncula. As características internas foram: forma do embrião e presença do endosperma. Para isso, as sementes foram seccionadas longitudinalmente com auxílio de bisturi e examinadas sob lupa de mesa com aumento de seis vezes. O comprimento, a largura e a espessura dos frutos e sementes foram medidos utilizando-se paquímetro digital com precisão de $\pm 0,2 \mathrm{~mm}$. Foi calculado o erro padrão da média.

As sementes foram escarificadas mecanicamente com lixa, após a retirada manual da carúncula, e imersas em solução de Benomyl a $10 \%$ por 30 minutos, sob agitação, e depois colocadas para germinar no substrato papel mata-borrão, na forma sobre papel, em caixas de plástico transparente e com tampa, em câmara de germinação a $30{ }^{\circ} \mathrm{C}$ e fotoperíodo de oito horas. Foram utilizadas quatro repetições de 20 sementes. O papel foi umedecido com solução de ácido giberélico (400ppm), até atingir o máximo de saturação e, em seguida, escorreu-se o excesso.

A germinação e o desenvolvimento da plântula foram observados diariamente, durante 40 dias, efetuando-se as descrições e ilustrações, de forma manual, com auxílio de lupa de mesa. Considerou-se como germinada a semente que apresentava emissão de radícula e como plântulas normais as que apresentavam folhas cotiledonares abertas. A 
terminologia utilizada foi baseada nos trabalhos de Damião Filho (1993) e Oliveira (1993).

\section{Resultados}

O fruto de J. elliptica é seco, com três cocas globosas, endocarpo lenhoso e deiscência explosiva. Essa deiscência explosiva ocorre quando os frutos estão secos, fazendo com que as cocas se fendam longitudinalmente, liberando as sementes (figuras 1,2).

A coloração do fruto maduro é castanha, a superfície é lisa, e o pericarpo apresenta duas zonas distintas: o exocarpo, película mais fina, e o endocarpo, mais grosso. Próximo à deiscência, o exocarpo desprende-se do fruto, dando-lhe um aspecto mais áspero. Os frutos têm, em média, 11,20 mm de diâmetro por $12,48 \mathrm{~mm}$ de comprimento e apresentam geralmente três sementes.

A semente é ovalada, de dorso convexo, endospérmica, de envoltório liso e marmoreado, apresentando carúncula presa na parte ventral. O hilo é visível na base e a rafe é bem marcada longitudinalmente na semente (figura 1C). As sementes apresentam, em média, 8,21 $\pm 0,68 \mathrm{~mm}$ de comprimento, 4,33 $\pm 0,21 \mathrm{~mm}$ de largura e 3,69 $\pm 0,18 \mathrm{~mm}$ de espessura. O embrião é reto, com cotilédones planos, foliáceos, arredondados, com nervação marcada e eixo hipocótilo-radícula cilíndrico e reto (figura 4).

Os estágios seqüenciais da germinação e do desenvolvimento da plântula são mostrados nas figuras 5-9. Com o intumescimento da semente e ruptura do envoltório, próximo à região do hilo, ocorre a emissão da radícula (figura 5), sendo a raiz principal branca. Normalmente cinco raízes são formadas, uma central e quatro periféricas. Essas raízes periféricas, denominadas adventícias, desenvolvem-se a partir do colo (figura 6). O tempo médio para germinação, considerada como emissão da radícula, é de 13 a 25 dias.

Concomitantemente à formação do sistema radicular ocorre o desenvolvimento do hipocótilo, de coloração branco-esverdeada. Os cotilédones são envolvidos inteiramente pelo endosperma (figuras 6,7), que é relativamente espesso e de coloração branca. Por volta de sete dias após a emissão da radícula, as folhas cotiledonares estão completamente expandidas (figura 8). O tipo de germinação é epígea e fanerocotiledonar. A duração da germinação e desenvolvimento da plântula varia de 20 a 32 dias.

A plântula considerada normal (figura 8) caracteriza-se por apresentar raízes principal e adventícias brancas, cônicas e pilosas; raízes secundárias finas, com pêlos radiculares, semelhantes aos da raiz principal; hipocótilo cilíndrico e glabro, apresentando espessamento em sua base, próximo à raiz, e folhas cotiledonares pecioladas, elípticas, verdes, margens lisas, ápice e base obtusas, peninérveas e nervuras opostas salientes na face abaxial. A porcentagem de plântulas normais foi de $46,6 \%$.

Em algumas sementes, durante o processo de germinação, ocorreu primeiramente a emissão e expansão das folhas cotiledonares; a plântula formada apresentou o hipocótilo atrofiado e o desenvolvimento da raiz foi tardio. Essas plântulas foram consideradas anormais (figura 9).

\section{Discussão}

O estudo sobre a morfologia de sementes faz-se necessário devido à importância dessas estruturas na identificação botânica (Oliveira \& Pereira 1987). A identificação morfológica de plântulas também permite caracterizar famílias, gêneros e até espécies, tendo sido bastante aplicada nos estudos de inventário florestal em regiões de clima temperado e tropical (Oliveira 1993).

Muitas características apresentadas pelos frutos de J. elliptica foram verificadas em frutos de outros gêneros de Euphorbiaceae como o mecanismo de propulsão que é explosivo. Barroso et al. (1999) ressaltam que todos são relacionados entre si e devem ter se originado de um ancestral comum.

Também, como em outros gêneros, exceto Amanoa Aubl. e Discocarpus Klotzsch., as sementes de J. elliptica e de todas as Euphorbiaceae têm endosperma farto, carnoso, rico em reservas oleaginosas (Barroso et al. 1999). Como na maioria das espécies dessa família, as sementes de J. elliptica apresentam germinação do tipo fanerocotiledonar. Exceções a esse padrão foram verificadas em Hevea sp., Hura crepitans L. e Omphalea diandra Vell. que têm germinação criptocotiledonar (Oliveira \& Pereira 1987). As sementes de $J$. elliptica diferem das de J. molissima Baill. (Oliveira \& Pereira 1987) por seu tamanho menor, sendo caracterizadas como pequenas (Figliolia et al. 1993). O processo de desenvolvimento radicular de J. elliptica é semelhante ao observado em Aleurites fordii Hemsl., Cnidoscolus polyanthus I.M. Johnst., J. molissima Baill. (Oliveira \& Pereira 1987) e J. curcas L. (Heller 1996), porém o tempo médio para emissão de radícula foi maior do que o observado em sementes de J. molissima. Outra diferença que pode ser considerada em relação a J. molissima é o formato 

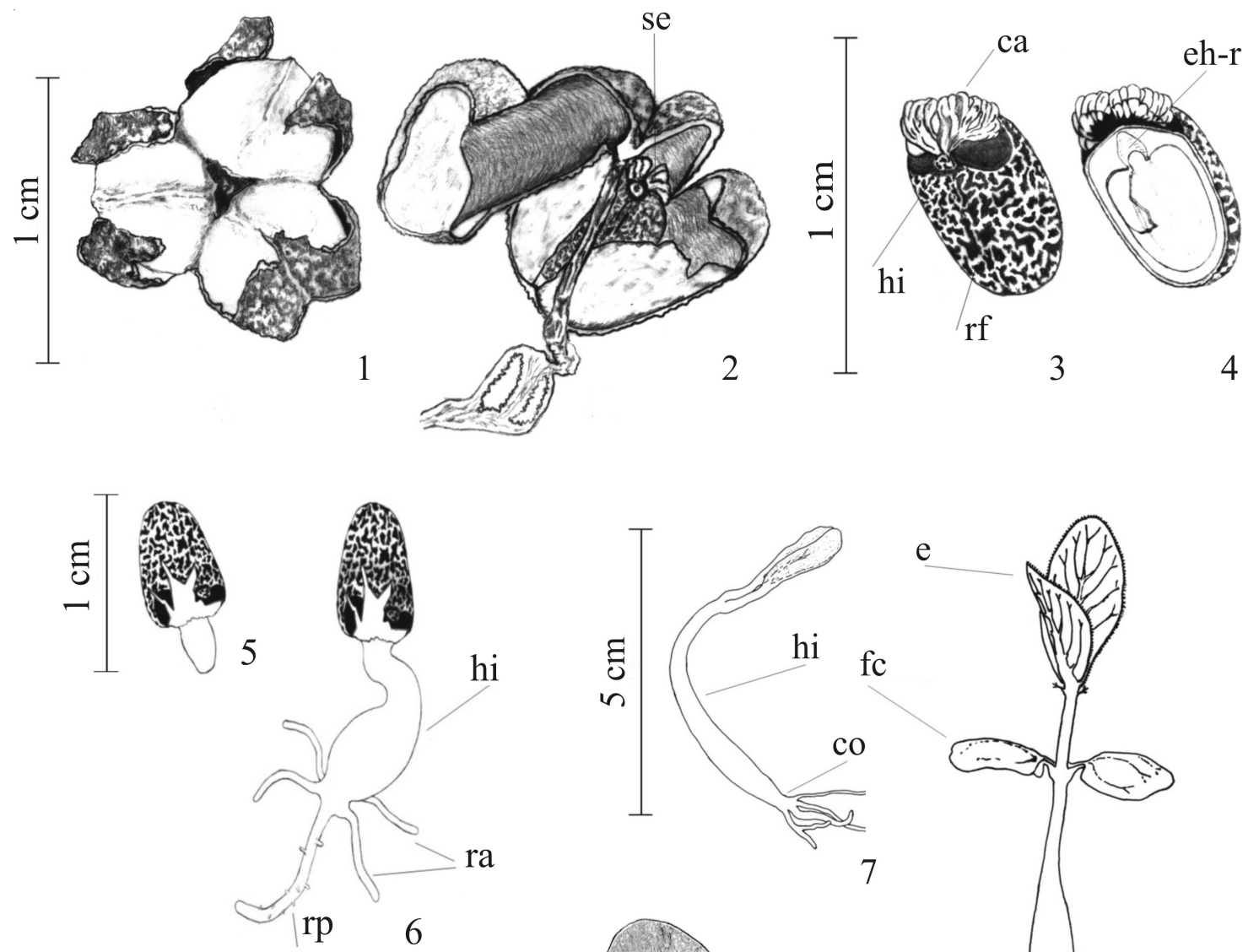

$\mathrm{e}$

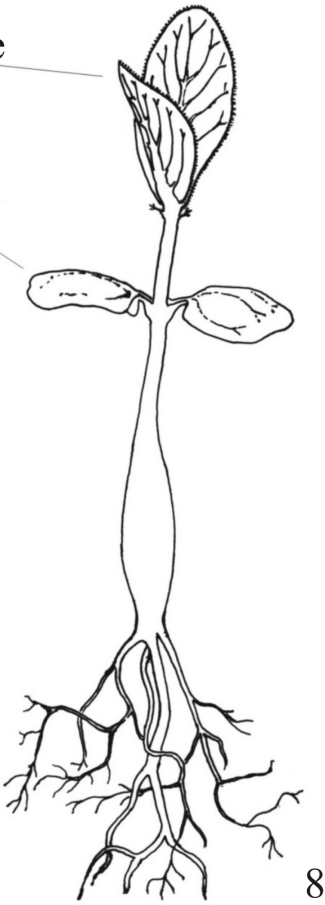

Figuras 1-9. J. elliptica. 1. Fruto. 2. Fruto aberto. 3. Semente. 4. Detalhe da semente mostrando o embrião. 5. Emissão da raiz primária. 6. Formação de raízes adventícias. 7. Expansão das folhas cotiledonares. 8. Planta normal. 9. Planta anormal. ( $\mathrm{se}=$ semente, $\mathrm{ca}=$ carúncula, $\mathrm{hi}=$ hilo, $\mathrm{rf}=\mathrm{rafe}, \mathrm{rp}=$ raiz primária, $\mathrm{ra}=$ raiz adventícia $, \mathrm{co}=\mathrm{colo}, \mathrm{fc}=$ folha cotiledonar, $\mathrm{e}=$ eófilo, eh-r $=$ ).

Figures 1-9. J. elliptica. 1. Fruit. 2. Opened fruit. 3. Seed. 4. Seed detail, showing the embryo. 5. Primary root emission. 6. Adventitious root formation. 7. Cotiledonary leaves expansion. 8. Normal seedling. 9. Abnormal seedling. (se - seed, ca - caruncle, $\mathrm{hi}=$ hilum, $\mathrm{rf}=$ raphe, $\mathrm{rp}=$ primary root, $\mathrm{ra}=$ adventitious root, $\mathrm{co}=$ stem base, $\mathrm{fc}=$ cotiledonary leaf, $\mathrm{e}=$ eophyll, eh-r $=$ ). 
elíptico da folha cotiledonar observado nas plântulas de J. elliptica. Folhas cotiledonares de J. molissima, apresentam forma ovada (Oliveira \& Pereira 1987).

O espessamento da base do hipocótilo é uma característica observada em outras espécies da família Euphorbiaceae, tais como A. fordii, A. moluccana (L.) Wild., H. crepitans, J. molissima, O. diandra e C. phyllacanthus Pax \& K. Hoffm. (Oliveira \& Pereira 1987). Plântulas de outras espécies com essa característica seriam consideradas anormais nos testes de germinação, mas não em $J$. elliptica. Todas essas plântulas deram origem a plantas normais, depois de transplantadas para o viveiro.

As plântulas consideradas anormais em J. elliptica apresentaram primeiramente a emissão de folhas cotiledonares, o hipocótilo atrofiado e quase nenhum desenvolvimento de raiz, além dessa ter sido emitida mais lentamente. Essas plântulas quando transplantadas não completaram seu desenvolvimento. Silva et al. (1995) encontraram esse mesmo tipo de anormalidade em plântulas de Luetzelburgia auriculata Ducke. Brasil (1992) considera como plântulas anormais aquelas que não mostram potencial para continuar seu desenvolvimento e dar origem a plantas normais, mesmo crescendo em solo de boa qualidade e sob condições favoráveis de umidade, temperatura e luz.

Labouriau (1983) destacou que em certas Rosaceae ocorre a produção de plantas com entre-nós anormalmente curtos, denominadas anãs fisiológicas, pois esse caráter indica a dormência remanescente nas sementes. $\mathrm{O}$ mesmo autor aponta para a possibilidade de que o nanismo fisiológico ocorra devido à ação hormonal, indicando que a causa talvez seja o desequilíbrio da distribuição desses hormônios, principalmente o ácido indolacético e as giberelinas.

As sementes de J. elliptica não germinam, mesmo escarificadas, quando colocadas em substrato umedecido com água; somente ocorre germinação quando o substrato é umedecido com ácido giberélico. Oliveira \& Camargo (2001) utilizaram esse mesmo tratamento para a superação de dormência de sementes dessa espécie. Mesmo quando submetidas ao tratamento para superação de dormência, a germinação não ultrapassa 50\%. Oliveira \& Pereira (1987) verificaram baixa porcentagem de plântulas normais em A. fordii (cerca de $3 \%)$, A. moluccana (9\%), C. polyanthus (4\%), H. crepitans (40\%) e J. molissima (20-30\%). O tempo até o desenvolvimento da plântula normal em $J$. elliptica varia de 20 a 32 dias. Em J. molissima esse período foi 7 a 16 dias. Em outros gêneros, 37 a 62 dias (Oliveira \& Pereira 1987).
A morfologia do fruto, da semente e da plântula de J. elliptica descrita e ilustrada neste trabalho foi suficientemente homogênea e confiável para caracterizar e identificar a germinação e os primeiros estágios de desenvolvimento desta espécie.

Agradecimentos - Ao Conselho Nacional de Desenvolvimento Científico e Tecnológico - CNPq pelo auxílio financeiro.

\section{Referências bibliográficas}

AÑEZ, R.B.S. 1999. O uso de plantas medicinais na Comunidade do Garcês (Cáceres, Mato Grosso). Dissertação de mestrado, Universidade Federal de Mato Grosso, Cuiabá.

BARROSO, M.B., MORIN, N.P., PEIXOTO, A.L. \& ICHASO, C.L.F. 1999. Frutos e sementes. Morfologia aplicada à sistemática de dicotiledôneas. Editora da UFV, Viçosa.

BRASIL, Ministério da Agricultura e Reforma Agrária. 1992. Regras para análise de sementes. SNAD, CLAV, Brasília.

DAMIÃO FILHO, C.F. 1993. Morfologia vegetal. Funep/Unesp, Jaboticabal.

DE LACRUZ-MOTA, M.G. 1997. Plantas medicinais utilizadas por raizeiros. Uma abordagem etnobotânica no contexto da saúde e da doença. Dissertação de mestrado, Universidade Federal de Mato Grosso, Cuiabá.

DUTRA, F.V., CALIXTO, J.B., MEDEIROS, Y.S. \& BRUM, R. 1996. Jatrophone inhibitis platelet rich plasma aggregation from man, rat and guinea-pig induce by different agents. Phytotherapy Research 10:271-273.

FERREIRA, R.A., BOTELHO, S.A., MALAVASE, M.M. \& DAVIDE,A.C. 1998. Caracterização morfológica de fruto, semente, plântula e muda de capitão-do-campo (Terminalia argentea Mart \& Zucc - Combretaceae). Revista Brasileira de Sementes 20:441-448.

FIGLIOLIA, M.B., OLIVEIRA, E.C. \& PIÑA-RODRIGUES, F.C.M. 1993. Análise de sementes. In Sementes florestais tropicais (I.B. Aguiar, F.C.M. Piña-Rodrigues \& M.B. Figliolia, eds.). Abrates, Brasília, p.137-174.

GUARIM NETO, G. 1996. Plantas utilizadas na medicina popular do Estado de Mato Grosso. Abeas, Brasília.

HELLER, J. 1996. Physic nut. Jatropha curcas L. Promoting the conservation and use of underutilized and neglected crops. Institute of Plant Genetics ans Crop Plant Research, Gatersleben/International Plant Genetics Resources Institute, Rome.

LABOURIAU, L.G. 1983. A germinação das sementes. Secretaria Geral da Organização dos Estados Americanos, Washington.

LABOURIAU, L.G., MARQUES I.F.M., LABOURIAU, M.L.S. \& HANDRO, W. 1963. Nota sobre a germinação de sementes de plantas de cerrados em condições naturais. Revista Brasileira de Biologia 23:227-237. 
MARTINI, L.H., SOUZA, C.R., MARQUES, P.B., CALIXTO, J.B., YUNES, R.A. \& SOUZA, D.O. 2000. Compounds extracted from Phyllantus and Jatropha elliptica inhibit the biding of $\left[{ }^{3} \mathrm{H}\right]$ Glutamate and $\left[{ }^{3} \mathrm{H}\right]$ GMP-PNP in rat cerebral cortex membrane. Neurochemical Research 25:211-215.

OLIVEIRA, E.C. 1993. Morfologia de plântulas. In Sementes florestais tropicais (I.B. Aguiar, F.C.M. PiñaRodrigues \& M.B. Figliolia, eds.). ABRATES, Brasília, p.175-214.

OLIVEIRA, A.C.B. \& CAMARGO, I.P. 2001. Efeito de diferentes substratos no crescimento de mudas de purga-de-lagarto (Jatropha elliptica M. Arg.). Revista Agricultura Tropical 5:57-65.

OLIVEIRA, E.C. \& PEREIRA, T.S. 1987. Euphorbiaceae Morfologia da germinação de algumas espécies. Revista Brasileira de Sementes 9:9-51.

POTT, A. \& POTT, V.J. 1994. Plantas do Pantanal. Embrapa, Centro de Pesquisa Agropecuária do Pantanal, Corumbá, MS.

SANTOS, F.A. \& SANT'ANA, A.E.G. 1999. Molluscicidal activity of the diterpenoids jatrophne and jatropholone A and B isolated from Jatropha elliptica (Pohl) M. Arg. Pytotherapy Research 13:660-664.
SILVA, L.M.M., MATOS, V.P., PEREIRA, D.D. \& LIMA, A.A. 1995. Morfologia de frutos, sementes e plântulas de Lutzelburgia auriculata Duck (pau-serrote) e Pterogyne nitens Tul (madeira nova do brejo) Leguminosae. Revista Brasileira de Sementes 17:154-159.

SILVA, S.M.P., COELHO, M.F.B. \& SILVA, A.M. 1998. Aspectos fenológicos de purga-de-lagarto (Jatropha elliptica M. Arg. - Euphorbiaceae) em Santo Antônio de Leverger - MT. Revista Brasileira de Biologia 58:301-306.

SOUZA, L.F. 1998. Estudo etnobotânico na comunidade de Baús: o uso de plantas medicinais (Município de Acorizal, Mato Grosso). Dissertação de mestrado, Universidade Federal de Mato Grosso, Cuiabá.

VAN DEN BERG, M.E. \& SILVA, M.H.L. 1988. Contribuição à flora medicinal de Mato Grosso do Sul. Acta Amazônica 18:9-22.

VIEIRA, R.E., SILVA, S.R., ALVES, R.B.N., SILVA, D.B., WETZEL, M.M.V.S., DIAS, T.A.B., UDRY, M.C. \& MARTINS, R.C. 2002. Estratégias para conservação e manejo de recursos genéticos de plantas medicinais e aromáticas: Resultados da $1^{\mathrm{a}}$ Reunião Técnica. Embrapa Recursos Genéticos e Biotecnologia, Ibama, CNPq, Brasília. 